\section{Study epidemiology of fake news}

The results of the 2016 US presidential election and the UK vote to leave the European Union (Brexit) have raised questions about the influence of fake online news and social-media 'echo chambers' (see also P. Williamson Nature 540, 171; 2016). The propagation of such information through social networks bears many similarities to the evolution and transmission of infectious diseases. Analysis of transmission dynamics could therefore provide insight into how misinformation spreads and competes online.

For example, disease strains can evolve and compete in a host population, much like rumours, and infections and opinions are both shaped by social contacts. Modelling of competing disease strains indicates that, as contacts become more localized, the diversity of circulating strains can increase (see C. O’ F. Buckee et al. Proc. Natl Acad. Sci. USA 101, 10839-10844; 2004). Network structure can also suppress the invasion of new disease strains (see G. E. Leventhal et al. Nature Commun. 6, 6101; 2015).

As more people turn to social networks as a primary news source, transmission models combined with appropriate data could help in exploring the dynamics of this new media landscape.

Adam Kucharski London School of Hygiene \& Tropical Medicine, $U K$.

adam.kucharski@lshtm.ac.uk

\section{Be wary of 'ethical' artificial intelligence}

Jim Davies's suggestion that we programme ethics into artificial intelligence meta-systems as a safeguard could well backfire by compromising our abilities to judge ethical implications

(Nature 538, 291; 2016).

In an earlier version of the future, robot lawnmowers and kitchen appliances promised us more leisure time. We now face the spectre of mass human displacement from a consumption-based economy by equipment that can do things much more efficiently than people can.

The 'age of information' promised global connectivity, but this has wrought distraction to a point at which only lurid excesses can focus our undivided attention on the society to which we all belong.

And as computer-generated imagery colonizes our imaginations, many are barely swayed by real violence (the wanton destruction of Syrian cities comes to mind). There is even evidence that video gaming driven by computer-generated imagery can alter a player's perception of acceleration and gravity (see, for example, A. B. Ortiz de Gortari and M. D. Griffiths Int. J. Hum. Comput. Interact. 30, 95-105; 2014) - compromising their decision-making skills in a world where real physics is the law. Such trends don't bode well for 'ethical' computers.

Michael Stocker Ocean

Conservation Research, Lagunitas, California, USA. mstocker@ocr.org

\section{New contender for most lethal animal}

Of some 3,500 species of mosquito, those of the genus Anopheles are widely considered to be the most dangerous because they transmit malaria. Malaria is decreasing, however, and other mosquito-borne diseases, such as dengue, chikungunya, Zika and yellow fever, are increasing (S. V. Mayer et al. Acta Tropica 166, 155-163; 2017). The mosquito Aedes aegypti, the primary carrier of these viruses, now constitutes an even greater threat (see also Nature 539, 17-18; 2016, and S. F. Dowell et al. Nature 540, 189-191; 2016).

Aedes mosquitoes have been transferring these viruses among African primates for millennia. One African primate (Homo sapiens) and one African Aedes (A. aegypti) have spread from Africa. Viruses adapted to both have spread with them. Yellow fever hit the developed world in the seventeenth century, dengue in the nineteenth, chikungunya in the twentieth, and now Zika in the twenty-first.

Scientists studying mosquitoborne viruses have catalogued hundreds more lurking in Africa. The world needs to take notice before these take hold and spread further. As Pliny the Elder (AD 23-79) wrote, "Ex Africa semper aliquid novi" ('there is always something new coming out of Africa').

Jeffrey R. Powell Yale University, New Haven, Connecticut, USA. jeffrey.powell@yale.edu

\section{Journals, agree on manuscript format}

An 'incorrectly' formatted manuscript submission risks immediate bounceback by the authors' chosen journal, irrespective of the value of its content. In my view, it would save time and frustration if the scientific community could agree on a uniform style for all journals.

There is no inherent advantage in customized formatting of references, for example, whether cited as F. R. Smith, P. Y. Young and G. T. Jones J. Interest. Sci. 2016, 85, 6700-6782, or as Smith, FR, Young, PY, Jones, GT (2016) J. Interest. Sci. 85: 6700-6782, or using other arbitrary variants in style and positioning of initials, year of publication and page span.

Research papers in the natural sciences are typically presented under the headings Abstract, Introduction, Methodology, Results, Discussion, Conclusions. Some journals do not use Abstract or Introduction headings; some put the Methodology section after the rest. No journal so far puts the title at the end of the paper.
Journals presumably insist on individual formatting styles as a distinguishing feature. I see no scientific merit in doing so. Cosmetic treatments should instead be reserved for enhancing the clarity of a manuscript's content.

Quanmin Guo University of Birmingham, UK.

q.guo@bham.ac.uk

\section{Vulture restaurants cheat ecosystems}

Vulture 'restaurants' across southern Europe are serving up carcasses in an attempt to rescue these endangered birds. We contend that such outlets are no true replacement for the naturally random food pulses associated with wildlife carrion.

When food is only randomly available, it supports the foraging of hundreds of invertebrate and vertebrate scavenger species, promoting co-existence of multiple species and thus ecosystem balance. By contrast, a predictable food supply tends to benefit only selected species (see, for example, A. Cortés-Avizanda et al. Front. Ecol. Environ. 14, 191-199; 2016) - griffon vultures (Gyps fulvus) in this case.

Furthermore, large predators are now expanding in Europe, contributing to the rewilding of many landscapes. Predation helps to stabilize food chains by buffering oscillations in the availability of carrion, which are linked to climate events and disease epidemics. Scavenger species that recover as a result of such ecological rewilding boost ecosystem functions and services derived from their feeding behaviour, for example by reducing the spread of disease.

We should stop providing services to nature through vulture restaurants and allow nature to provide services to us. Ainara Cortés-Avizanda, Henrique Miguel Pereira CIBIO-InBIO, University of Porto, Vairão, Portugal. hpereira@idiv.de 